\title{
Categorías y problemas de análisis de las fuentes medievales del sermón moderno. La comunicación popular como acto aprehensible*
}

Problems and categories on the analysis of medieval sources. Popular communication as an aprehensible action

(4) Carolina Losada

CONICET - Universidad de Buenos Aires, Argentina

Fecha de Recepción: . Fecha de aceptación: .

\section{Resumen}

La predicación popular y su registro histórico - los sermones - se han convertido en las últimas décadas en un recurso invaluable para el estudio de la cultura europea tardomedieval y moderna. A partir del desarrollo del campo han surgido nuevas perspectivas teóricas así como técnicas propias del estudio de la sermonística que valorizan su estudio. En este paper se presentan algunos de los debates y, en conexión a aquellos, una hermenéutica no filológica del abordaje de la predicación popular y sus fuentes. El objetivo es reivindicar el recurso como un registro de comunicación oral que puede ser estudiado y comprendido más allá de su contenido, y que permite una nueva mirada sobre la Europa pre-gutengberiana.

\begin{abstract}
Popular preaching and its historical sources - sermons - have became during the last decades in invaluable resources on Late Medieval and Modern culture. Since the development of the field, new theories and technics had arisen. This paper present some of the debates on the field and, connected with those, and hermeneutic on the sources. The purpose is to vindicate medieval sermon as an oral registry of communication that can be studied and understood beyond its content in order to enrich the History of pre-Gutenbergian Europe.
\end{abstract}

\section{La predicación popular y sus fuentes}

Los registros de los sermones populares se han convertido en un recurso invaluable para interrogar los modos de la comunicación cultural, religiosa y política durante

* Artículo entregado en el marco de las VII Jornadas de Reflexión Histórica: Las formas del conflicto religioso y de la violencia simbólica en el espacio cultural europeo (siglos XIV a XVIII): actores, dispositivos, escenarios, estrategias", organizadas por el Instituto de Historia Antigua y Medieval, (Facultad de Filosofía y Letras, Universidad de Buenos Aires), el 5 de diciembre de 2018

Palabras clave

predicación sermón medieval comunicación hermenéutica

Keywords

preaching medieval sermon communication hermeneutics 
el medioevo y la modernidad (Mayne Kienzle, 2000). Fundamental para discernir los dispositivos de trasmisión propias de una sociedad primariamente oral, el sermón constituye un discurso público, que pretende ser masivo y que se enuncia con el objeto de persuadir a la audiencia, en principio para la reforma moral, pero también utilizado para promover las cruzadas, proyectos rebeldes y agendas políticas. Los predicadores -profesionales de la palabra- fueron los agentes de la comunicación medieval por antonomasia, su trayectoria y accionar resulta esencial para comprender los modos en que circulaba la palabra, de carácter sagrado y político. Las ordenes mendicantes, nacidas a la luz de la renovación cultural y religiosa del siglo XII, se dedicaron desde su origen con fervor a la tarea de custodiar una ortodoxia y ortopraxia a través de sermones que constituía el leit motiv de su existencia (Labal, 2000).

En ese tono, este paper se propone enunciar de modo sistemático herramientas teóricas y hermenéuticas para el abordaje de esta clase de fuentes. Bien por fuera del ejercicio filológico, la propuesta que aquí se plantea pretende repensar los sermones como discursos situados en un contexto. Además, se busca expresar marcos teóricos que acompañen mejores análisis y comprensión de las fuentes.

Este ejercicio implica comprender el sermón como un dispositivo complejo, enunciado por agentes altamente capacitados en teología y técnicas para la práctica de la comunicación oral. Las claves para comprender las formas en que la palabra circula, se valora y legitima en el período están grabadas en los sermones. La voz del predicador presenta en la reconstrucción relativa de evento de la predicación un episodio específico de la comunicación pública medieval con mayor alcance simultáneo. En ese sentido, proponemos aquí, junto a las estrategias de abordaje del objeto histórico, algunas ideas que han renovado la lectura del pasado en términos del análisis de las formas y alcances de la comunicación oral.

El objetivo eminente del sermón medieval es la persuasión. En tanto es una práctica largamente experimentada por las comunidades judías, cristianas y musulmanas, la predicación es una tarea de profesionales con una extensa experiencia en la práctica de comunicar y reformar (Bataillon, 1982: 213-26; Martin, 1988; Delcorno, 1994: 1-21). Las estrategias de los predicadores eran el producto de una combinación del oficio aprendido y de la creatividad propia del agente, que permiten vislumbrar una reflexión pública, medianamente consensuada y abiertamente expresada de la sociedad a la que se dirige el discurso reformador.

\section{Debates y nuevos marcos teóricos}

El desafío de actualización de la mirada sobre las fuentes sermonísticas medievales viene azuzado por el importante desarrollo del campo del estudio de los sermones medievales en los últimos 40 años. Especialmente desde la década de 1990, la expansión ha sido inmensa e innovadora (Morrissey, 1999: 111-23). Esto no sólo a causa de la incorporación de la fuente como recurso a partir de la innovadora propuesta de estudio del exemplum que Le Goff y Schmitt hicieran en la década de 1980, sino además por la formación y desarrollo del campo (Bremond, Le Goff y Smitt, 1982; Berlioz y Polo de Beaulieu, 1993: 1-9). La definición del sermón moderno que impera hoy día es producto de esos estudios: el sermón como un género literario central en las vidas de los cristianos y judíos europeos durante la Edad Media, un discurso esencialmente oral, dicho en la voz de un predicador que se dirige a una audiencia para instruirla y exhortarla en algún tema concerniente a la fe o la moral basado en un texto sagrado. ${ }^{1}$

La incansable labor de los sermonistas ha propiciado debates que resultan necesarios a la hora de comprender la gravitación de la predicación medieval, no solo por el descubrimiento y redescubrimiento de fuentes de toda clase, que permiten echar luz a
1. Este trabajo se ha convertido en la obra ineludible para cualquiera intere sado en la predicación, los sermones o los dispositivos comunicacionales en el período medieval y moderno (Mayne Kienzle, 2000: 143, 151). 
las formas y límites de la cultura popular a través del análisis de la palabra de grandes predicadores, sino también con el diseño de nuevas instancias de comprensión para estos sermones y su impacto en la sociedad en la que se produjeron. Considero aquí tres problemas cuyo desarrollo tiene potencial transformador sobre la mirada de la historia tardomedieval y moderna. El primero es la trascendencia de la oralidad y su ubicuidad como dispositivo comunicacional primordial en las sociedades en las que la comunicación escrita no está generalizada, en segundo lugar el problema de la omnipresencia de la predicación en el mundo europeo tardomedieval y temprano moderno y la dimensión más o menos masiva del mensaje; por último, considerar el valor teológico y teórico del contenido de los sermones en el marco de su producción y realización.

Lo que los estudios actuales sobre oralidad medieval demuestran es que las formas de decodificar los mensajes culturales son múltiples y que la situabilidad de esos mensajes es lo que los embarga de interés histórico (Ong, 1996; Gellrich, 1995). La interseccionalidad entre los grupos sociales y culturales que se califican como puramente orales o letrados evidencia que los mensajes nunca son unidimensionales en términos de destinación, que jamás son impermeables en sentido y objetivos, pues están necesariamente situados $y$, entonces, no son exclusivos de un grupo social. ${ }^{2}$ Eso no significa que la comunicación se produzca descontextualizada de las relaciones de poder. Muy por el contrario, para poder aprehender las formas del dominio político del mundo medieval es necesario notar que los actos comunicativos son parte del ejercicio de poder de un modo que semeja una red antes que una vía vertical, y que la oralidad juega un rol esencial en los ejercicios de propaganda, afirmación y legitimación política.

La oralidad es una tecnología que todos los miembros activos de una sociedad manejan. La escritura no es una forma predominante de comunicación ni aún después del desarrollo de la imprenta, sino que funciona como subsidiaria y autónoma de la oralidad, complementaria de ésta. Y la comunicación, entonces, se realiza en su mayor parte a través de lo oral antes que lo escrito, pues la escritura limita el alcance y la comunicabilidad del mensaje. No es nuestro propósito el de invertir el argumento original de Lévi-Strauss -que iguala técnicas de registro escrito con evolución social-, sino más bien abonar a una concepción distinta de los mecanismos de la oralidad en tanto ubicuos, heterogéneos y desarticulados en términos de su preponderancia histórica como esenciales para cualquier estudio de la sociedad. ${ }^{3}$ Para comprender la esencialidad del estudio de estos problemas hay que asumir que la palabra dicha constituye un conjunto de técnicas culturales que se imparten, se educan junto a la lengua. Con ellas se construyen categorías intrínsecas de decodificación cultural que aparecen luego como intuitivas, no racionalizadas (Zumthor, 1987) ${ }^{4}$. No obstante, el análisis que se enmarca en la cuestión de la oralidad, la literatura medieval y la literatura oral tiene la tendencia a recaer en los mismos mecanismos académicos de valorización de los discursos escritos como si éstos tuvieran todavía una pátina de superioridad respecto de los orales. ${ }^{5}$

Si trascendemos la dicotomía entre oralidad y escritura - sin negar su carácter distintivo - llegamos a la conclusión de que existen niveles de comunicabilidad y de comunicación. La circulación de la palabra se produce y reproduce de forma radicular, atravesada de índices de valoración ligados intrínsecamente a jerarquías establecidas en una sociedad rígidamente estamental. Además tiene la característica de efectivizarse a través de actos que se sitúan en la cotidianeidad de modo múltiple y abrumadoramente real. La comunicación social entre personas y grupos es un hecho, exista un registro o no de ella; es por eso necesario preguntarse por los dispositivos culturales de que se sirve para comprender su impacto desde la perspectiva histórica (cfr. Claret García Martínez, 2007: 31).

De estas ideas se colige otra, más polémica aún, que busca incluir la noción de "comunicación masiva" al análisis de las fuentes sermonísticas. David D`Avray propone que, dado que los monjes mendicantes eran educados a lo largo y a lo ancho de Europa con el mismo
2. Tomo la idea de interseccionalidad respecto de los grupos sociales al considerar a la sociedad más como una red interconectada que como una pirámide formada por compartimentos estancos. Sin descartar la noción de jerarquía y de sometimiento social propia de las sociedades desiguales, lo que reivindica la noción de interseccionalidad es la necesidad de comprender los grupos sociales como interconectados y dependientes (Grimson, 2011: 121).

3. Esta es la idea detrás de la tesis del Paréntesis Gutenberg (Pettitt, 2009).

4. En particular Introducción y 89-93.

5. Esta recaída se hace enmascarada en un discurso que no desvaloriza lo oral pero sin embargo rastrea con insistencia el registro escrito y su historia (Deyermond, 2005: 29-50). 
método - leyendo los mismos libros, instados a reproducir mensajes similares, con foco en la reforma moral y de costumbres - la homogeneización de las creencias e ideas y el respaldo a las autoridades constituidas, es posible entender la predicación como un sistema normatizado puesto en función por las órdenes mendicantes. En tanto sistema, su condición de estructurado sobre la reiteración sistemática de ideas regentes estructurado sobre la reiteración sistemática de premisas permite revisar la noción de comunicación masiva en su concepción más ampliada. Así, si entendemos el alcance de una información como una repetición sostenida multimedial, que impacta en un amplio porcentaje de la sociedad, la predicación popular con sus miles de monjes pululando por los caminos de Europa como un sistema aceitado de transmisión eficiente de ideas. ${ }^{6}$

A esa se agrega otra que, articulada con las otras, entiende los discursos orales de los sermones populares constituyen un tipo específico de discurso escolástico por estructura y por contenido, que debe ser considerado como una categoría particular de teología vernácula. Es decir, dada la profunda formación teológica de los predicadores es necesario entender sus discursos como formas de expresión teórica que constituyen en su originalidad novedades de corte teórico y no meras anomalías procedentes de la forma discursiva. En ese sentido, la predicación constituiría una traducción y una creación de las ideas que se debatían en los ámbitos académicos, cuya circulación ampliada no perjudicaría su valor teórico (McGinn, 1997: 1-14; Corbari, 2013).

\section{Aspectos del abordaje}

Los sermones en tanto fuentes orales textualizadas son las herramientas a través de las cuales es posible abordar aspectos específicos de la producción y reproducción de la cultura del período en contexto (Muessig, 2002a: 3-9). Múltiples aspectos de la fuente son incorporados al análisis, en tanto, al reponer las condiciones materiales de la producción del discurso se busca descubrir como diversos aspectos impactan en el sermón como producto cultural. Aquí se expresan dos aspectos del abordaje de la producción homilética tardomedieval y moderna que permiten una comprensión del contexto de producción: escena y audiencia.

La escena del sermón constituye la fisicalidad de la predicación. Algunas piezas de esa escena podían ser controladas por el predicador, otras recaían en una tradición específica sobre dónde y cómo se predicaba en los espacios públicos y otras tantas escapaban de cualquier control voluntario ${ }^{7}$. El sermón se establecía como acto liminal, pues si bien respondía a una ritualidad, su realización lo convertía en una agencia del todo original y significativa en su repetición y su originalidad.

En la práctica, la prédica tenía lugar en la iglesia principal de la ciudad. Si ésta no era lo suficientemente amplia, siempre era posible colocar un púlpito fuera y se predicaba en la plaza frente a la iglesia. Había, no obstante, variantes: si el predicador famoso era un monje regular entonces predicaría en la iglesia de su orden; si había sido contratado por los magistrados lo haría en la catedral; y si existía algún conflicto en torno a su presencia el lugar de predicación podía ser fuera de la misma. La llegada de un predicador y sus sermones conmocionaban a la población urbana, pues, así como otras fiestas públicas, la predicación popular era una instancia de reafirmación de la identidad social y de la gloria, belleza y riqueza de una ciudad (Lawrance, 2010: 147-84).

La estrategia más práctica para la reposición del contexto del sermón ha sido acudir a registros alternativos, como las fuentes urbanas, las historias de los reyes, las cartas, etc. Por caso, en una relación de la predicación de Vicent Ferrer de 1412 en Castilla, el autor refiere que el predicador llegó en las horas de la tarde a la ciudad de Toledo y que a pesar de no haber sido convocada a hacer ninguna clase de bienvenida por
6. Véase D’Avray (2005), Akae (2005).

7. En el año 2013 se publicó on-line un proyecto digital llamado Virtual Paul's Cross Project (perteneciente a la North Carolina State University) en el que trabajó un equipo dedicado a la predicación moderna y preocupado por comprender mejor el entorno real de los sermones. El proyecto consiste en una instalación digital en la que se reproduce la Plaza de la Catedral de San Pablo en Londres que intenta imitar los posibles contextos del sitio de la predicación del famoso sermón de John Donne del Powder Day (5 de noviembre) de 1622. A esa reconstrucción digital se le agregaron marcadores acústicos que permiten al visitante posicionarse en alguno de los lugares de la plaza y oir una prueba del sermón desde esa distancia (http://vpcp.chass.ncsu.edu/) Este ejercicio permite un acercamiento a las formas reales de la predicación. 
el clero o por los magistrados, la gente salió espontánea y masivamente a recibirlo (Cátedra García, 1984: 235-309). Es evidente que el arribo del predicador se enmarcaba en formas teatrales significativas, en algunas fuentes se lo describe acompañado de unas 500 personas que oraban en voz alta; otras, refieren que la entrada a la ciudad se hacía con los hombres de la compañía precediendo al predicador, al tiempo que se flagelaban con látigos y gritaban ipiedad, piedad! (Châtellier, 1997: 4) Semejante espectáculo resultaba impactante y convocante. La rimbombante llegada de Ferrer y su séquito puntuaba desde el inicio la importancia espiritual de su presencia en la ciudad.

Dicen las fuentes que Fray Vicente, anciano y pequeño de contextura, llegó en un humilde asno que lo llevó hasta la puerta de la iglesia. Ya dentro bendijo a los presentes y se retiró a descansar.

A la mañana siguiente a su llegada, entonces, Ferrer se dirigió a la iglesia a predicar en un púlpito que para tal fin se había dispuesto dentro. El corresponsal describe toda la situación como no satisfactoria, el púlpito era muy alto, había demasiada gente y no se oían las palabras del sermón. Dadas estas dificultades se decide construir un púlpito alternativo fuera de la ciudad, en un lugar suficientemente amplio y abierto para que la gente pudiera acudir con masividad.

Cabe destacar que el predicador no controla una infinidad de variables, el clima, el ruido ambiente, etc. Este último va a estar impactado por factores acústicos que van desde la arquitectura del espacio hasta la cantidad de gente que acudió a oír el sermón. El problema del "ser oído" era clave en las reflexiones sobre la actividad del predicador, y la necesidad de que la voz del predicador fuera inteligible era tan importante como que captara la atención. El predicador debía superar los límites espaciales con un esfuerzo vocal y estrategias de predicación (Berlioz y Polo de Beaulieu, 2013: 21; Mayne Kienzle, 2002: 89-124).

\section{La audiencia}

Como actividad pública y colectiva que compone una de las instancias de sociabilidad urbana, al hallarse en la misma categoría de actividad social que romerías y procesiones, el sermón incluye a todo el entramado social urbano. Omnipresente, insistente, agitada, la masa que compone la audiencia no tiene límites fijos ni precisos; en tanto es socialmente heterogénea se recluta entre todos los sectores de la sociedad (Zumthor, 1987: 69). Las ars praedicandi muestran una seria preocupación por adaptar el sermón a la audiencia; y si bien la mayoría de las colectáneas de sermones podían distinguirse por el momento litúrgico de predicación, existe un tipo de colecciones que son caracterizados por la audiencia ante la que eran predicados. ${ }^{8}$

Las audiencias dejan en el sermón una marca indeleble que es evidente en el texto a partir del uso y abuso de la segunda persona singular y de las formas verbales imperativas. Las imágenes de una audiencia fiel y recogida en las palabras del predicador, que aparentemente reflejan tanto los sermones textualizados como las representaciones de los predicadores, no son neutrales (Berlioz y Beaulieu, 2013). Es posible hallar en sermones reportados a los predicadores pedir silencio y reprender a las personas que hablan durante la predicación, de lo cual se deriva la frecuencia de las interrupciones. Por otra parte, la participación de la audiencia en la predicación era más requerida de lo que las fuentes dejan entrever: oyentes apáticos eran síntoma de un sermón ineficiente. ${ }^{9}$ La idea de una audiencia silenciosa, más propia de algunos espectáculos modernos que del mundo medieval es irrisoria. El público vitorea, abuchea, llora, y así participa en el desarrollo del espectáculo de la predicación. Como forma intermedia entre el ritual religioso y el entretenimiento, era un evento social (Stillman, 2006: 113;
8. Un análisis del carácter específico de los sermones ad status puede hallarse en Muessig (2002b: 255-76).

9. Existe un sermón en el que el mismo Bernardino se indigna con un grupo de mujeres y las conmina a abandonar la iglesia (Polecritti, 2000: 132). 
Postlewate, 2007: 116). Las estrategias discursivas de los predicadores incluían a las audiencias como parte integrante en el diseño, construcción y realización del sermón, pues constituían un segmento activo del acto de comunicación.

En tal sentido hay que considerar la experiencia de la escucha del sermón como una al mismo tiempo colectiva y exclusiva, que se deriva en múltiples interpretaciones del contenido de lo predicado. Como forma intermedia entre el ritual religioso y el entretenimiento, era un evento en sí mismo y así fue concebida y diseñada por los predicadores más exitosos, que utilizaron un amplio espectro de estrategias visuales, sonoras y teatrales para obtener y mantener la atención de quienes la oían.

Bernardino da Siena, cuyas alocuciones a las mujeres son entendidas como un aparato discursivo destinado a valorizar el rol femenino en la reforma de costumbres y el control de lo cotidiano, encuentra un límite cuando habla de sexo frente a jóvenes vírgenes, el cual queda registrado en los sermones vulgares predicados en Siena en $1427 .{ }^{10} \mathrm{Al}$ principio del sermón Bernardino agradece a las sabias madres que han llevado a sus hijas a oírlo hablar sobre el amor marital, tal y como les había solicitado el día anterior y señala, al mismo tiempo, la cantidad de ausencias en la audiencia. Indignado por la situación, Bernardino inicia una larga reprimenda en la que acusa a las mujeres de promover el daño sobre sus propias familias. Por toda respuesta, ellas abandonan masivamente la catedral sienesa. Se lee en el sermón "No se vayan, no se vayan; esperen, así quizás oigan alguna cosa que no conozcan” (Polecritti, 2000: 50-55).

Las estrategias discursivas de los predicadores incluían necesariamente a las audiencias, porque su presencia las convertía en parte integrante del acto de comunicación. Sermones y campañas se diseñaban con el objetivo de ser eficientes ante una audiencia, siempre considerando el público, con claro sentido pedagógico (Losada, 2012: 823-38).

\section{Conclusión}

Los indicadores históricos de los sermones medievales, la escenificación y la audiencia, permiten comprender la fuente como un emergente complejo de la comunicación medieval. El objetivo de la comunicación trascendía al contenido y lo permeaba, sin por ello desmerecerlo. Esta clase de fuentes, cuyo origen es la oralidad, demuestra que los dispositivos comunicacionales cobran un sentido nuevo a la luz de una comprensión cabal de su contexto de producción. Textos en contexto, su existencia depende de la realización del acto de predicación. El objetivo del sermón medieval es la persuasión de la audiencia a que se acoja a las normas católicas, se reforme y se adecúe a una verdadera cristiandad en términos morales. El contenido, traducción de los lineamientos doctrinales de la Iglesia, se modeliza siempre en la realización.

La audiencia del sermón medieval es dinámica, amplia y heterogénea. El discurso, por ende, está diseñado para apelar a esta audiencia cuya complejidad es inalcanzable. A medio camino entre la normatización teológica y el entretenimiento, el sermón medieval es una fuente multiforme y compleja.

Las estrategias para profundizar el impacto del mensaje potencian el estudio del contenido de ese mensaje, pues al analizar la predicación medieval no podemos dejar de lado la conciencia compartida del predicador y la audiencia de que eso que están viviendo, ese espacio de transición espiritual es una experiencia religiosa auténtica. La escena, tanto en su configuración formal como en lo generado por el predicador y en lo contingente moldea necesariamente el mensaje religioso y moral que el sermón medieval pretende manifestar.
10. Siena, Predicaziones volgare 1427 . 


\section{Bibliografía}

》 Akae, Yuichi (2005). A Mendicant Sermon Collection from Composition to Reception. The Novum opus dominicale ofJohn Waldeby. Turnhout: Brepols.

"Bataillon, L.-J. (1982). «Intermédiaires entre les traités de morale pratique et les sermons: les distinctiones bibliques alphabétiques». En Les genres littéraires dans les sources théologiques et philosophiques médiévales, 213-26.

» Berlioz, J. y Polo de Beaulieu, M. A. (2013). "The Preacher Facing a Reluctant Audience According to the Testimony of Exempla". Medieval Sermon Studies 57, n. 1 (octubre): 16-28.

»Berlioz, J. y Polo de Beaulieu, M. A. (1998). “Le Groupe de recherche sur les exempla médiévaux (Paris)", en Les exempla médiévaux, 1-9.

»Berlioz, J. y Polo de Beaulieu, M. A. (1993). "Le Groupe de recherche sur les exempla médiévaux (Paris)”. En Cahiers du Centre de Recherches Historiques, 11, pp. 1-9.

»Bremond, J., Le Goff, y schmitt J. C. (1982). L'exemplum, Typologie des resources del Moyen Äge Brepols. Turnhout.

" Cátedra García (1984-1985). “La predicación castellana de San Vicente Ferrer”, Boletín de la Real Academia de Buenas Letras de Barcelona 39, pp. 235-309

»Châtellier (1997). The Religion of the Poor: Rural Missions in Europe and the Formation of Modern Catholicism, C.1500-C.180o Cambridge: Cambridge University Press.

"Claret García Martínez, A. (2007). La escritura transformada. Oralidad y cultura escrita en la predicación de los siglos XV al XVII. Huelva: Universidad de Huelva.

"Corbari, E. (2013). Vernacular Theology: Dominican Sermons and Audience in Late Medieval Italy. Berlin: Walter de Gruyter.

"D’Avray, D. (2005). Medieval marriage: symbolism and society. Oxford: Oxford University Press.

"Delcorno, C. (1994). "Professionisti della parola: Predicatori, giullari, concionatori”, en Tra storia e simbolo.

" Deyermond, A. (2005). “La literatura oral en la transición de la Edad Media al Renacimiento”, Acta Poética 26.1.

»Gellrich, J. (1995). Discourse and Dominion in the Fourteenth Century: Oral Contexts of Writing in Philosophy, Politics, and Poetry. Princeton: Princeton University Press.

» Grimson, A. (2011). Los límites de la cultura Siglo XXI. Buenos Aires.

"Labal, P. (2000). Los cátaros: herejía y crisis social. Critica.

"Lawrance, J. N. H. (2010). "Homily and harangue in medieval Spain: the sermon and crowds". Revista de poética medieval, 24: 147-84.

"Losada, C. M. (2012). “El adversario del profeta: estrategias discursivas de conversión de los judíos y reforma de costumbres en un sermón de Vicente Ferrer". Bulletin hispanique 114.2: 823-38.

» Martin, H. (1988). Le métier de prédicateur en France septentrionale á la fin du moyen âge 1350-1520. Histoire. Paris. 
» Mayne Kienzle, B. (2002). "Medieval sermons and their performance: theory and record", en Preacher, sermon and audience in the Middle Ages. Brill: Turnhout, pp. 89-124.

» Mayne Kienzle, B. (2000). The sermon (Typologie), vol. 81-83, Typologie des sources du moyen âge occidental. Brill: Turnhout.

» McGinn, B. (1997). “Introduction. Meister Eckhart and the Beguines in the Context of Vernacular Theology". en Meister Eckhart and the Beguine Mystics, 1-14.

" Morrissey, M. (1999). “Interdisciplarity and the Study of Early Modern sermons". The Historical Journal 42.4: 1111-23.

" Muessig, C. A. (2002a). "Preacher, sermon and audience in the Middle Ages: an introduction". En Preacher, sermon and audience in the Middle Ages, 3-9.

»Muessig, C. A. (2002b). “Audience and preacher: “ad status” sermons and social classification". En Preacher, sermon and audience in the Middle Ages, 255-76.

» Ong, W. J. (1996). Oralidad y escritura. Tecnologías de la palabra. México, D.F.: Fondo de Cultura Economica.

"Pettitt, T. (2009). "Containment and Articulation: Media, Cultural Production, and the Perception of the Material World". http://web.mit.edu/comm-forum/ mit6/papers/Pettitt.pdf.

»Polecritti, C. (2000). Preaching Peace in Renaissance Italy. Bernardino de Siena $\varepsilon$ his Audience, Washington. Washington: The Catholic University Press.

"Postlewate, L. (2007). "Introduction", en Acts and texts. Performance and ritual in the Middle Ages and the Renaissance, 7-16.

"Stillman, R. E. (2006). Spectacle and public performance in the late Middle Ages and the Renaissance. Vol. 113. Studies in medieval and reformation traditions. Leiden.

»Zumthor, P. (1987). La letra y la voz de la literatura medieval. Cátedra. Buenos Aires. 